Rules or Consequences? The Role of Ethical Mindsets in Moral Dynamics

Gert Cornelissen

Universitat Pompeu Fabra and Barcelona GSE

Michael R. Bashshur

Singapore Management University

Julian Rode

Helmholtz Centre for Environmental Research - UFZ

Marc Le Menestrel

Universitat Pompeu Fabra

Author Note

Gert Cornelissen, Department of Economics and Business, Universitat Pompeu Fabra and Barcelona GSE; Michael R. Bashshur, Lee Kong Chian School of Business, Singapore Management University; Julian Rode, Department of Environmental Politics, Helmholtz Centre for Environmental Research - UFZ; Marc Le Menestrel, Department of Economics and Business, Universitat Pompeu Fabra.

This research was supported by the grant ECO2008-01768 from the Spanish Ministry of Science and Innovation. 
Correspondence concerning this article should be addressed to Gert Cornelissen, Department of Economics and Business, Ramon Trias Fargas 25-27, Barcelona 08005, Spain. Phone: (+34) 93542 2731. Email: gert.cornelissen@upf.edu 


\begin{abstract}
Recent research on the dynamics of moral behavior has documented two contrasting phenomena - moral consistency and moral balancing. Moral balancing refers to the phenomenon whereby behaving (un)ethically decreases the likelihood of doing so again at a later time. Moral consistency describes the opposite pattern - engaging in (un)ethical behavior increases the likelihood of doing so later on. Three studies support the hypothesis that individuals' ethical mindset (i.e., outcome-based versus rule-based) moderates the impact of an initial (un)ethical act on the likelihood of behaving ethically in a subsequent occasion. More specifically, an outcome-based mindset facilitates moral balancing and a rule-based mindset facilitates moral consistency.
\end{abstract}

Keywords: moral balancing, moral consistency, ethical mindsets, ethical behavior. 
Rules or Consequences? The Role of Ethical Mindsets in Moral Dynamics

A British online newspaper recently headlined a story on moral dynamics with "How going green may make you mean - ethical consumers less likely to be kind and more likely to steal". The studies by Mazar and Zhong (2010) that were reported on in the newspaper article demonstrated how provoking an environmentally friendly product choice, by offering mostly green options, made participants more likely to cheat on a subsequent task than participants who did not have the opportunity to make a similarly green choice. While a provocative headline, it was inaccurate. Clearly, the term "ethical consumers" would be appropriate only if participants' (environmental) values had been assessed. The fact that the newspaper's sensationalist misinterpretation was quickly adopted or independently produced by various media sources illustrates that "doing good leads to doing bad" is an intriguing idea that runs contrary to most people's intuition.

Researchers have been slow to recognize the dynamics inherent in moral behavior. Previous research on moral or ethical behavior was mostly limited to studying moral reasoning (e.g., Kohlberg, 1969) and other factors that influence episodic or oneshot behavior, like individual differences (e.g., centrality of moral values; Aquino \& Reed, 2002) and situational influences (e.g., Haney, Banks, \& Zimbardo, 1973).

Recently, however, a number of studies on moral self-regulation have demonstrated that one's recent behavioral history is an important factor in shaping current moral conduct (e.g., Monin \& Jordan, 2009; Zhong, Liljenquist, \& Cain, 2009). Interestingly, seemingly inconsistent effects have been reported. Moral balancing (Nisan, 1991) refers to the observation that engaging in an (un)ethical behavior at one point in time reduces 
the likelihood of doing so in a subsequent situation (Merritt, Effron, \& Monin, 2010; Sachdeva, Iliev, \& Medin, 2009). For example, after committing to helping a foreign student, participants were less willing to donate money to charity (Khan \& Dhar, 2006). In contrast, moral consistency refers to the opposite pattern. Gino, Norton, and Ariely (2010) demonstrated that participants who wore counterfeit sunglasses were more likely to cheat, compared to participants who wore branded sunglasses. In short, it appears that engaging in an (un)ethical act can have opposing effects on subsequent decisions. In the current paper, we investigate the potential reconciling role of the ethical mindset an individual is in as a moderator of these effects.

\section{Moral Self-regard}

From a social psychological perspective, moral self-regard is one element of a multifaceted, dynamic, and motivational self-concept (Markus \& Wurf, 1987). In general, people strive to enhance and preserve a positive self-concept (Greenwald, 1980) and use multiple strategies to achieve that end. For example, one may assign larger weights to the dimensions of the self for which one holds a favorable view, favor and selectively attend to self-flattering information, put down threatening others, or, importantly for our studies, try to match behavior with one's aspiration levels. For those who place a strong emphasis on moral self-regard, behaving ethically is an important source of self-worth (Crocker \& Knight, 2005). An individual's moral aspiration level does not only motivate ethical behavior, but also serves as a reference point against which the position of the actual self can be evaluated (Higgins, 1996). Moral self-regard is a function of this evaluation, with moral self-regard improving when moral selfperception approaches or exceeds the aspiration level. People tend to experience emotional distress if they are not living up to their moral aspirations (Higgins, 1987; 
Klass, 1978) and in some cases engage in moral behaviors to compensate for previous failures (i.e., moral balancing).

Cultivating the moral self often conflicts with pursuing immediate self-interest. To understand how individuals solve that conflict, it is important to consider that the moral aspiration level does not equate to moral perfection, but rather to a reasonable level of moral behavior (Nisan, 1991) for that individual. The moral self-regulation literature has repeatedly argued that people tune their actions for their moral selfperception to fluctuate around the moral aspiration level. A moral slip motivates corrective behavior, while (self-perceived) ethical behavior liberates one to engage in a subsequent, less moral action (e.g., Merritt, et al., 2010; Sachdeva, et al., 2009).

Other research has suggested an alternative role for past behavior; as a source of information to learn about the self (Bem, 1972). In this perspective individuals infer their moral status by analyzing their previous behavior. Because of the established finding that people prefer their current behavior to be consistent with their previous behavior, and that they use behavioral consistency as a decision heuristic (Albarracín \& Wyer, 2000; Cialdini, Trost, \& Newsom, 1995) this can result in a preference for consistency in moral behavior. Gino, et al. (2010) account for the increase of cheating when participants wear counterfeit sunglasses by suggesting that wearing counterfeit goods sends a certain signal to the self about the self ("apparently I am a cheater"). The effect was observed even when participants did not choose which glasses to wear, but were assigned a counterfeit product by the experimenter. Other studies have shown that a person's behavior can be manipulated even more subtly, by retroactively suggesting a re-attribution of a previous act by means of a social label (Cornelissen, Dewitte, Warlop, \& Yzerbyt, 2007). This provokes subsequent choices that are consistent with the new (externally induced) self-attribution. 
In short, an (un)ethical act can have opposing effects on subsequent behavior. In some instances, we observe moral consistency, whereas in other cases, moral balancing occurs. How can these seemingly contradictory observations be reconciled? We suggest that the individual' ethical mindset moderates the influence of an initial behavior on subsequent actions.

\section{Moral Frameworks and Ethical Mindsets}

Two prominent frameworks in (Western) moral philosophy are deontology and consequentialism (e.g., Hunt \& Vitell, 2006; Singer, 1991). In a deontological perspective, what makes an act right is its conformity to a moral norm (Alexander \& Moore, 2008). Moral behavior follows principles that impose duties and obligations, such as not to break promises, not to lie, and not to harm the innocent. In other words, when taking a deontological perspective an individual adopts a rule-based mindset. In a consequentialist framework, whether an act is morally right depends on the consequences of that act (Sinnott-Armstrong, 2008). In other words, when taking a consequentialist perspective, one behaves according to an outcome-based mindset. Past work has demonstrated that this distinction is not exclusively philosophical, but that individuals consider it meaningful when reflecting on their behavior (Spranca, Minsk, \& Baron, 1991).

We propose that the ethical mindset one adopts moderates whether engaging in an (un)ethical act leads to moral balancing or moral consistency. An outcome-based mindset produces an appraisal of the consequences of each behavioral alternative, both for the individual and for others involved, and of what those alternatives would imply for the moral self. When confronted with a goal conflict between cultivating the moral self and pursuing self-interest, thinking in terms of outcomes allows the individual to be flexible when trading off the moral self and immediate self-interest (Mazar \& Ariely, 
2006; Monin \& Jordan, 2009). Balancing both motives over time permits establishing an acceptable compromise between both. Hence, after choosing an ethical course of action which benefitted mostly others, the individual feels more licensed to compensate and benefit self-interest. We predict that individuals in an outcome-based mindset treat their previous behavior as a signal that indicates whether they are morally licensed or need to morally compensate.

Moral rules, on the other hand, do not easily lend themselves to such trade-offs (Baron \& Spranca, 1997; Tetlock, Kristel, Elson, Green, \& Lerner, 2000). A rule derives its validity from its generalization across different instances (Shaw, 1993). In a rule-based mindset, inconsistently following (ethical) rules threatens an individual's sense of psychological integrity (Festinger, 1957). Additionally, research suggests that once individuals internalize deontological rules, they follow them rather mindlessly and, when questioned, experience difficulties in justifying why they follow that rule (Haidt, 2001). We predict that individuals in a rule-based mindset use their previous behavior as a guide and are more likely to behave in a morally consistent manner.

We tested these predictions in three laboratory studies.

\section{Study 1}

In this study we tested our hypothesis that a consequential mindset leads to moral balancing, whereas a deontological mindset results in moral consistency. We first measured participants' dominant ethical mindset. We then asked participants to recall an (un)ethical act in which they had recently engaged and observed how that influenced levels of ethical behavior in a subsequent task. We expected those participants identified as being in a rule-based mindset to use the ethicality of their recalled behavior as a guide, such that those who recalled an ethical behavior would behave more fairly than 
those who recalled an unethical act. For those in an outcome-based mindset, we expected the opposite effect.

\section{Participants and Procedure}

A total of 86 undergraduate students participated in a one-hour study in return for a $4 €$ show-up fee. They were seated in semi-closed cubicles in front of a computer. We first measured participants' dominant ethical mindset using a moral dilemma scenario (the Trolley Dilemma). After 20 minutes of non-related filler tasks, we asked participants to recall either an ethical or unethical behavior in which they had recently engaged. We subsequently observed behavior in a Dictator Game (DG).

\section{Materials}

The trolley dilemma. The trolley dilemma (Thomson, 1986) was designed to pit consequentialist and deontological ethics against each other. Participants are asked to imagine the following scenario: A runaway trolley is headed for five people who will be killed if it proceeds on its present course. The only way to save them is to hit a switch that will turn the trolley onto an alternate set of tracks where it will kill one person instead of five. Consequential ethics prescribes flipping the switch as the appropriate behavior because the consequences of that act, the death of one person, are less undesirable than the consequences of doing nothing (i.e., the death of five people). Deontological ethics maintains that doing something that hurts an innocent person is wrong, so flipping the switch is ethically unacceptable. Participants were asked whether it is morally appropriate to flip the switch. Those who believed that it was appropriate were assumed to generally employ an outcome-based mindset. Those who believed it was not appropriate were assumed to employ a rule-based mindset.

Dictator Game. Participants were randomly paired with another participant in the room. Then they read the instructions of the DG. These mentioned that one 
individual in their pair would be assigned the role of the decider. The decider would receive 10 coins of 50 eurocent each, and would decide on the division of that money between them in whatever way s/he chose. All participants were told that they were assigned the role of the decider and were asked to indicate how many coins they wanted to give to the receiver. At the end of the session, participants were paid according to the allocations made in the game.

\section{Results}

Based on their responses to the trolley dilemma, out of 86 participants, we classified $48(56 \%)$ as having a dominant outcome-based mindset and $38(44 \%)$ as having a rule-based mindset. An ANOVA on the number of coins given to the receiver showed a significant interaction effect of ethical mindset and ethicality of the recalled behavior $\left(F(1,82)=8.71, p<.01, \eta^{2}=.10\right.$, see Figure 1$)$. Those in an outcome-based mindset gave less coins after recalling an ethical act $(M=2.37, S D=2.31)$ than after recalling an unethical act $(M=3.71, S D=2.13, F(1,46)=4.29, p<.05)$. Participants in a rule-based mindset gave more coins after recalling an ethical act $(M=3.18, S D=$ 2.40) than after recalling an unethical act $(M=1.76, S D=1.92, F(1,36)=4.63, p<$ $.04)$. There was no main effect of ethicality of the recalled behavior $(F<1)$ nor of ethical mindset $\left(F(1,82)=1.50, p=.22, \eta^{2}=.02\right)$.

Please insert Figure 1 about here

\section{Discussion}

Our findings support our predictions. Participants in an outcome-based mindset showed a balancing effect: recalling something unethical they did in the past made them more generous in the DG than participants who recalled an ethical act. Participants in 
rule-based mindset showed a consistency effect: those recalling an ethical act were more generous than those recalling an unethical act.

\section{Study 2}

The goal of the second study was to provide additional evidence for the role of ethical mindsets as a moderator of moral dynamics, rather than being a proxy of the true moderator, by manipulating instead of measuring them (Spencer, Zanna, \& Fong, 2005).

\section{Participants and Procedure}

A total of 107 undergraduate students participated under the same conditions as in Study 1. First, we manipulated ethical mindset (rule-based versus outcome-based) and ethicality of an initial act (ethical or unethical). We asked half of our participants to remember an episode in the past where they did something ethical, and the other half to remember an episode where they did something unethical. In addition, half of the individuals in each group were instructed to think about a behavior that was (un)ethical "because it hurt/benefitted other people" (outcome-based). The others thought about a behavior that was (un)ethical "because you did not/did your duty to follow an ethical norm or principle" (rule-based). As a dependent measure, participants made an allocation decision in a DG. Participants were also asked to respond to the Trolley Dilemma as a manipulation check for our mindset manipulation.

\section{Induction of ethical mindsets}

To induce the appropriate mindset, we provided elaborate instructions. The instructions defined ethicality as either a function of consequences or in terms of rule compliancy, and provided three prototypical examples. Subsequently, we asked participants to provide an example of a behavior - not necessarily their own - that is (un)ethical because of either its consequences or rule compatibility. This induced the 
intended mindset in participants before they reflected on their own behavior.

Additionally, to reinforce the mindset manipulation, in the outcome-based condition we asked them who was benefited or hurt in their example, and in the rule-based condition we asked which rule was respected or violated. We then asked participants to recall an instance in their own recent past when they themselves behaved (un)ethically, either because of the consequences or because of the rule compliancy of that behavior. Again we asked them who benefited and who were hurt in the outcome-based condition, and which rule was followed or violated in the rule-based condition. In a control condition, participants were asked to describe what they do on a typical Friday.

\section{Results and Discussion}

As a manipulation check we analyzed participants' judgments in the trolley dilemma. The proportion of participants that considered it appropriate to flip the switch (i.e., those who followed outcome-based arguments) was $67 \%$ (16 out of 24 ) in the control group, $78 \%$ (31 out of 40) in the outcome-based group and 50\% (21 out of 42) in the rule-based group $\left(\chi^{2}(2)=6.00 ; p<0.05\right)$. This suggests that the manipulation was successful.

An ANOVA analyzing the effect of the 4 experimental and the control condition on the number of coins donated in the DG was statistically significant $(F(4,102)=3.23$, $p<.02, \eta^{2}=.11$, see Figure 2).

Please insert Figure 2 about here

Simple contrasts did not indicate differences between the control condition and the experimental conditions ${ }^{\mathrm{i}}$. To further analyze the obtained effects, we dropped the control condition and analyzed the interaction effect of ethical mindset and ethicality of 
the recollected behavior on the number of coins given in the DG. There were no main effects of ethical mindset or ethicality $\left(F^{\prime} \mathrm{s}<1\right)$, but the interaction effect of both factors was significant $\left(F(1,79)=12.09, p<.01, \eta^{2}=.13\right.$; see Figure 2). Participants in an outcome-based mindset gave more coins in the DG after they recalled an unethical act $(M=3.47, S D=1.78)$ than those who recalled an ethical act $(M=1.86, S D=1.96 ; F(1$, $39)=4.94, p=.03)$. In other words, participants in an outcome-based mindset showed a moral balancing effect. In contrast, participants in a rule-based mindset gave more coins in the DG after recalling an ethical act $(M=3.20, S D=1.91)$ than after recalling an unethical act $(M=1.91, S D=1.93 ; F(1,40)=7.32, p=.01)$. In other words, these participants showed a moral consistency effect.

After replicating our hypothesized moderation effect, we wanted to evaluate the generalizability of our findings by changing the context to cheating behavior. Also, we wanted to test our initial idea about the underlying mechanism. To do so, we measured moral self-regard in the third study.

\section{Study 3}

\section{Participants and Procedure}

A total of 135 undergraduate students participated under the same lab set up and fee as Studies 1 and 2. We manipulated ethical mindset and ethicality of a recalled act with the same task used in Study 2. We then observed behavior in a cheating task and measured participants' moral self-regard.

\section{Materials}

Cheating task. We used a cheating task adapted from Mazar, Amir, and Ariely (2008). We gave participants a sheet with 20 matrices containing 12 three-digit numbers. They had four minutes to find a pair of numbers in each matrix that added up to 10 . They were told they would receive 50 Eurocent for each solved matrix. After four 
minutes, they self-reported the number of solved matrices on the computer and threw the worksheet in a recycling bin. After the experiment was done, we retrieved the worksheets. Based on one number on the sheets that differed for each participant we matched the worksheets with the participants and calculated the extent to which participants had overstated their performance.

Moral self-regard. We measured moral self-regard with the personality items of Aquino and Reed's (2002) moral identity scale. In order to assess the discrepancy of perceived self with the aspired self we asked participants to answer on a 7-point scale "Compared to the person I would like to be, right now I feel..." for nine traits: Caring, Compassionate, Fair, Friendly, Generous, Hardworking, Helpful, Honest, Kind.

\section{Results}

There was a significant effect of our manipulation on the degree of overreporting performance (i.e., cheating; $\mathrm{F}(4,130)=2,51 ; \mathrm{p}<.05, \eta^{2}=.07$, see Figure 3 ). As in Study 2, simple contrasts did not indicate significant differences between the control condition and the experimental conditions ${ }^{\mathrm{ii}}$. We dropped the control condition to further analyze the effects of our manipulations. There were no main effects of ethical mindset or ethicality of the recalled behavior $\left(F^{\prime} s<1\right)$, but the interaction effect of both was significant $\left(F(1,103)=8.10 ; p<.01, \eta^{2}=.07\right.$, see Figure 3$)$ and replicated the pattern found in Studies 1 and 2. Participants in a rule-based mindset cheated to a smaller extent after recalling an ethical act $(M=1.00, S D=2.25)$ than after recalling an unethical act $(M=2.23, S D=2.10, F(1,51)=4.22 ; p<.05)$, thus displaying a consistency effect. Those in an outcome-based mindset cheated more after recalling an ethical act $(M=1.74, S D=2.03)$ than after recalling an unethical act $(M=0.74, S D=$ $1.68, F(1,52)=3.89 ; p=.05)$, in line with a balancing effect. 
Please insert Figure 3 about here

Interestingly, we found a main effect of ethicality of the recalled act on participants' moral self-regard $\left(F(1,102)=11.64 ; p<.01, \eta^{2}=.10\right)$. As expected, those recalling an ethical act considered themselves to be more ethical individuals $(M=4.77$, $S D=.77)$ than those recalling an unethical act $(M=4.28, S D=.72)$. Neither the effect of ethical mindset $(F(1,102)=1.60, p=.21)$ nor the interaction between ethical mindset and ethicality $(F<1)$ was significant. A moderated mediation analysis (Preacher, Rucker, \& Hayes, 2007) revealed a conditional indirect effect of ethicality of the recalled act on the level of cheating, mediated by participants' moral self-regard, see Figure 4. The mediation was conditional on participants' ethical mindset. More specifically, both the effects of ethicality of the recalled act on moral self-regard $(b=$ $0.49, S E=0.15, p<.01)$, and the interaction effect of moral self-regard and ethical mindset on overstating of correctly solved matrices $(b=-1.11, S E=0.53, p<.05)$ were significant. The indirect effect of ethicality of the recalled act on cheating, mediated by moral self-regard, was significant in the outcome-based condition $(Z=-2.12, p<.05)$, but not in the rule-based condition $(Z=-.41, p=.68)$.

Please insert Figure 4 about here

\section{Discussion}

This study demonstrates that the moderating effect of ethical mindsets extends to other areas of ethical behavior, such as cheating. Additionally, we tested the mediating role of moral self-regard in the shaping of balancing and consistency effects. Individuals in an outcome-based mindset seem to attend to their moral self-regard and balance their 
behavior. A positive self-regard liberates the individual temporarily from the need to cultivate the moral self, and allows pursuing selfish interests without suffering aversive affective consequences. A negative level activates a mechanism to restore the moral self-regard, leading to more ethical behavior. In contrast, in a rule-based mindset, a parsimonious response based on behavioral consistency results in moral consistency effects.

\section{General Discussion}

In this paper, we provided empirical support for the hypothesis that ethical mindsets moderate how an individual's behavioral history shapes current ethical behavior. A rule-based mindset facilitates moral consistency effects, whereas an outcome-based mindset leads to moral balancing. This was demonstrated both when measuring participants' ethical mindset as an individual difference variable (Study 1) and after manipulating it (Study 2 and 3), establishing its causal role.

The framework we developed reconciles two streams of literature that produced seemingly conflicting findings (moral balancing and moral consistency). The insights provided by this paper help predict under which conditions we can expect larger moral consistency, and understand why. Further, we demonstrate that the two dominant perspectives in (Western) moral philosophy (i.e., consequentialism and deontology) find a counterpart in individuals' cognition, and that the mindset adopted may have important behavioral implications. Future research should study whether stable interindividual differences exist regarding the dominance of either mindset, or whether environmental factors (including the framing of messages in campaigns promoting ethical behavior) mostly determine which mindset is employed. We also speculated on and found preliminary evidence for the role that moral self-regard plays as a mediating 
construct in moral balancing and consistency effects. Further research is required to establish that role. 


\section{References}

Albarracín, D., \& Wyer, R. S. (2000). The cognitive impact of past behavior: Influences on beliefs, attitudes, and future behavioral decisions. Journal of Personality and Social Psychology, 79(1), 5-22.

Alexander, L., \& Moore, M. (2008). Deontological ethics. In E. N. Zalta (Ed.), The Stanford Encyclopedia of Philosophy. Stanford, CA: Metaphysics Research Lab, Center for the Study of Language and Information, Stanford University.

Aquino, K., \& Reed, A. (2002). The Self-Importance of Moral Identity. Journal of Personality and Social Psychology, 83(6), 1423-1440.

Baron, J., \& Spranca, M. (1997). Protected Values. Organizational Behavior and Human Decision Processes, 70(1), 1-16.

Bem, D. J. (1972). Self-perception theory. In L. Berkowitz (Ed.), Advances in Experimental Social Psychology (Vol. 6, pp. 1-62). New York: Academic Press.

Cialdini, R. B., Trost, M. R., \& Newsom, J. T. (1995). Preference for consistency: The development of a valid measure and the discovery of surprising behavioral implications. Journal of Personality and Social Psychology, 69(2), 318-328.

Cornelissen, G., Dewitte, S., Warlop, L., \& Yzerbyt, V. (2007). Whatever people say I am, that's what I am: Social labeling as a social marketing tool. International Journal of Research in Marketing, 24(4), 278-288.

Crocker, J., \& Knight, K. M. (2005). Contingencies of Self-Worth. Current directions in psychological science, 14(4), 200-203.

Festinger, L. (1957). A theory of cognitive dissonance: Stanford University Press.

Gino, F., Norton, M. I., \& Ariely, D. (2010). The Counterfeit Self. Psychological Science, 21(5), 712-720. doi: 10.1177/0956797610366545 
Greenwald, A. G. (1980). The totalitarian ego: Fabrication and revision of personal history. American Psychologist, 35(7), 603-618. doi: 10.1037/0003066x.35.7.603

Haidt, J. (2001). The emotional dog and its rational tail: A social intuitionist approach to moral judgment. Psychological Review, 108(4), 814-834.

Haney, C., Banks, C., \& Zimbardo, P. (1973). Interpersonal dynamics in a simulated prison. International Journal of Criminology \& Penology, 1(1), 69-97.

Higgins, E. T. (1987). Self-discrepancy: A theory relating self and affect. Psychological Review, 94(3), 319-340. doi: 10.1037/0033-295x.94.3.319

Higgins, E. T. (1996). The "self digest": Self-knowledge serving self-regulatory functions. Journal of Personality and Social Psychology, 71(6), 1062-1083. doi: $10.1037 / 0022-3514.71 .6 .1062$

Hunt, S. D., \& Vitell, S. J. (2006). The General Theory of Marketing Ethics: A Revision and Three Questions. Journal of Macromarketing, 26(2), 143-153. doi: $10.1177 / 0276146706290923$

Khan, U., \& Dhar, R. (2006). Licensing Effect in Consumer Choice. Journal of Marketing Research, 43(2), 259-266.

Klass, E. T. (1978). Psychological effects of immoral actions: The experimental evidence. Psychological Bulletin, 85(4), 756-771.

Kohlberg, L. (1969). Stage and sequence: The cognitive-developmental approach to socialization. In D. A. Goslin (Ed.), Handbook of socialization theory and research (pp. 347-480). Chicago, IL: Rand McNally.

Markus, H., \& Wurf, E. (1987). The Dynamic Self-Concept: A Social Psychological Perspective. Annual Review of Psychology, 38(1), 299-337. doi: doi:10.1146/annurev.ps.38.020187.001503 
Mazar, N., Amir, O., \& Ariely, D. (2008). The Dishonesty of Honest People: A Theory of Self-Concept Maintenance. Journal of Marketing Research, 45(6), 633-644.

Mazar, N., \& Ariely, D. (2006). Dishonesty in Everyday Life and Its Policy Implications. Journal of Public Policy \& Marketing, 25(1), 117-126. doi: 10.1509/jppm.25.1.117

Mazar, N., \& Zhong, C.-B. (2010). Do Green Products Make Us Better People? Psychological Science, 21(4), 494-498. doi: 10.1177/0956797610363538

Merritt, A. C., Effron, D. A., \& Monin, B. (2010). Moral Self-Licensing: When Being Good Frees Us to Be Bad. Social and Personality Psychology Compass, 4(5), 344-357. doi: 10.1111/j.1751-9004.2010.00263.x

Monin, B., \& Jordan, A. H. (2009). The dynamic moral self: A social psychological perspective. In D. Narvaez \& D. K. Lapsley (Eds.), Personality, identity, and character: Explorations in moral psychology. (pp. 341-354). New York, NY US: Cambridge University Press.

Nisan, M. (1991). The Moral Balance Model:Theory and Research Extending Our Understanding of Moral Choice and Deviation In W. M. Kurtines \& J. L. Gewirtz (Eds.), Handbook of Moral Behavior and Development (Vol. 3). Hillsdale, New Jersey: Lawrence Erlbaum Associates.

Preacher, K. J., Rucker, D. D., \& Hayes, A. F. (2007). Addressing Moderated Mediation Hypotheses: Theory, Methods, and Prescriptions. Multivariate Behavioral Research, 42(1), 185-227. doi: 10.1080/00273170701341316

Sachdeva, S., Iliev, R., \& Medin, D. L. (2009). Sinning Saints and Saintly Sinners. Psychological Science, 20(4), 523-528. doi: 10.1111/j.1467-9280.2009.02326.x Shaw, W. H. (1993). Social and personal ethics. Belmont, CA: Wadsworth. Singer, P. (1991). A Companion to ethics. Oxford: Blackwell Reference. 
Sinnott-Armstrong, W. (2008). Consequentialism. In E. N. Zalta (Ed.), The Stanford Encyclopedia of Philosophy Stanford, CA: Metaphysics Research Lab, Center for the Study of Language and Information, Stanford University.

Spencer, S. J., Zanna, M. P., \& Fong, G. T. (2005). Establishing a causal chain: Why experiments are often more effective than mediational analyses in examining psychological processes. Journal of Personality and Social Psychology, 89(6), $845-851$.

Spranca, M., Minsk, E., \& Baron, J. (1991). Omission and commission in judgment and choice. Journal of experimental social psychology, 27(1), 76-105.

Tetlock, P. E., Kristel, O. V., Elson, S. B., Green, M. C., \& Lerner, J. S. (2000). The psychology of the unthinkable: Taboo trade-offs, forbidden base rates, and heretical counterfactuals. Journal of Personality and Social Psychology, 78(5), 853-870.

Thomson, J. J. (1986). Rights, restitution and risk : essays in moral theory. Cambridge, MA: Harvard University.

Zhong, C.-B., Liljenquist, K., \& Cain, D. M. (2009). Moral self-regulation: Licensing and compensation. In D. De Cremer (Ed.), Psychological perspectives on ethical behavior and decision making. (pp. 75-89). Charlotte, NC US: Information Age Publishing. 


\section{Figures}

Figure 1. The interaction effect of ethical mindset and ethicality of the recalled act on the number of coins donated in a DG (Study 1). Error bars represent standard errors.

5
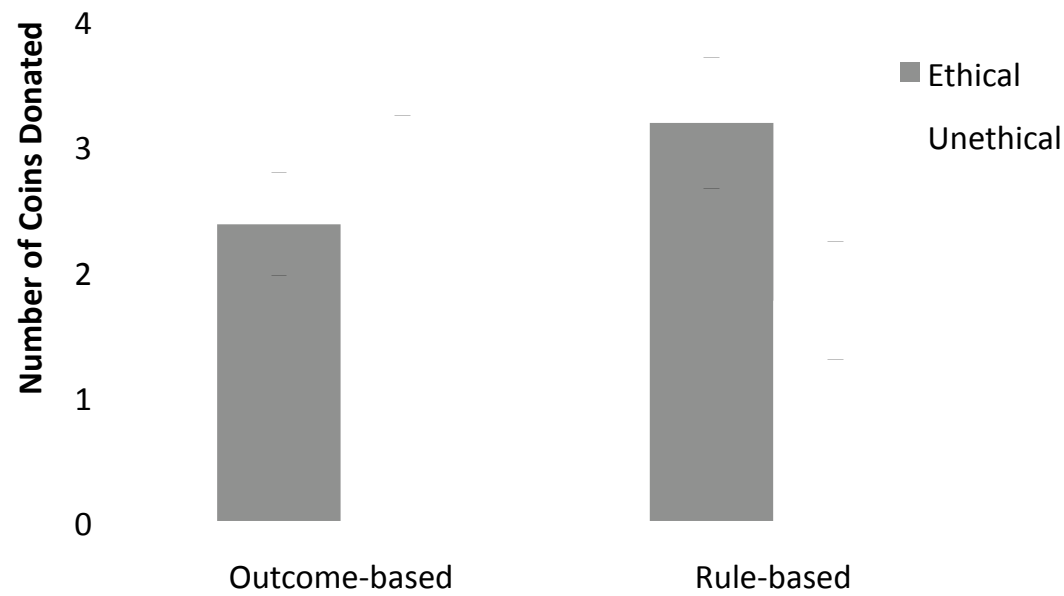

Ethical Mindset 
Figure 2. The interaction effect of recalling an (un)ethical act and ethical mindset on the number of coins donated in a DG (Study 2). Error bars represent standard errors.

5

4.5

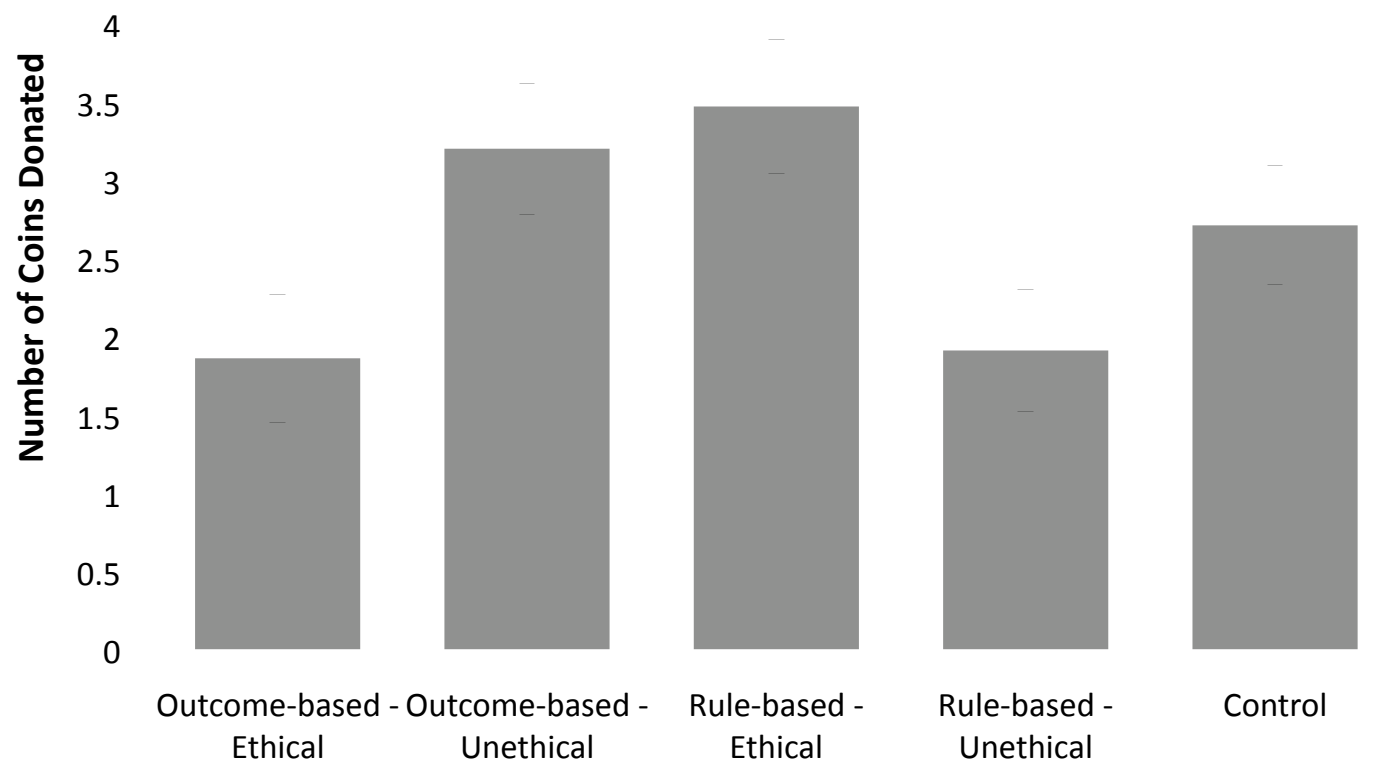


Figure 3. The interaction effect of recalling an (un)ethical act and ethical mindset on cheating (Study 3). Error bars represent standard errors.

4

3.5

3

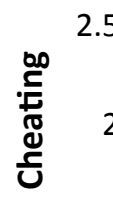

1.5

1

0.5

0

Outcome-based - Outcome-based - Rule-based Ethical

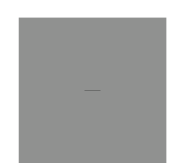
Unethical

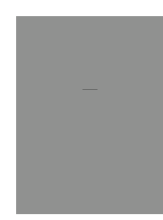

Ethical

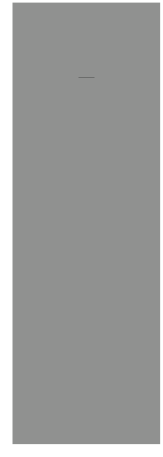

Rule-based Unethical

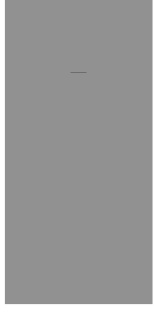

Control 
Figure 4. Path diagram of the moderated mediation model (Study 3).

Ethical mindset

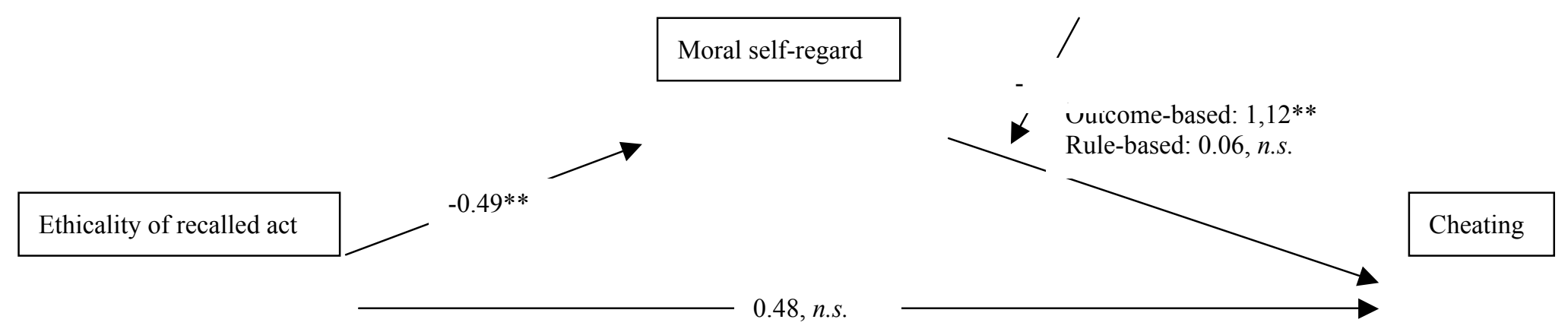

Note. ${ }^{*} p<.05, * * p<.0$ 